\title{
Frequency and Early Neonatal Mortality Related to Anomalies of Birth Weight and Gestational Age in Rural Areas: A Case of the General Reference Hospital of Lubao (Lomami Province, Democratic Republic of Congo)
}

\author{
Bukasa Héman Kabemba ${ }^{1,2,3 *}$, Ebondo Patrick Kasendue ${ }^{3}$, Muteba André Shiku ${ }^{4,5}$, \\ Nsomue Gentil Kabingie6, Mposhi Djolin Ngiele3 ${ }^{3}$, Tshite John Kitengie ${ }^{3}$, \\ Mulaba Gustave Ilunga ${ }^{3}$, Kabiswe Joelle Pungue ${ }^{7}$, Ebondo David Kalonda ${ }^{8}$, \\ Kabemba Pavlov Lukamba ${ }^{4}$
}

\begin{abstract}
${ }^{1}$ Department of Nursing Sciences, Higher Institute of Medical Techniques of Kalemie, Kalemie, Democratic Republic of Congo ${ }^{2}$ Department of Public Health, Faculty of Health Sciences, University Institute of Congo, Moba, Democratic Republic of Congo ${ }^{3}$ Department of Nursing Sciences, Higher Institute of Medical Techniques of Lubao, Lubao, Democratic Republic of Congo ${ }^{4}$ Department of Nursing Sciences, Higher Institute of Medical Techniques of Tshofa, Tshofa, Democratic Republic of Congo ${ }^{5}$ Department of Nursing Sciences, Higher Institute of Medical Techniques of Kamana, Kamana, Democratic Republic of Congo ${ }^{6}$ Department of Internal Medicine, Faculty of Medicine, University of Kabinda, Kabinda, Democratic Republic of Congo ${ }^{7}$ Department of Public Health, Faculty of Medicine, University of Kalemie, Kalemie, Democratic Republic of Congo ${ }^{8}$ Department of Nursing Education and Administration, Higher Institute of Medical Techniques of Lubao, Lubao, Democratic Republic of Congo

Email: ‘hemanuska@gmail.com, bossmen.patrick@gmail.com, andreshikum@gmail.com,djolinngiele@gmail.com, johnkitengie@gmail.com
\end{abstract}

How to cite this paper: Kabemba, B.H., Kasendue, E.P., Shiku, M.A., Kabingie, N.G., Ngiele, M.D., Kitengie, T.J., et al. (2017) Frequency and Early Neonatal Mortality Related to Anomalies of Birth Weight and Gestational Age in Rural Areas: A Case of the General Reference Hospital of Lubao (Lomami Province, Democratic Republic of Congo). Open Access Library Journal, 4: e3433.

https://doi.org/10.4236/oalib.1103433

Received: February 6, 2017

Accepted: March 25, 2017

Published: March 28, 2017

\begin{abstract}
Birth weight anomalies (Macrosomy and Dysmaturity) and gestational age (premature and post-term) are a real public health problem, especially in resourceconstrained countries. The newborn is exposed to great morbidity and mortality. This study aims to determine the frequency and early neonatal mortality related to anomalies in birth weight and gestational age in our environment. This is a retrospective and descriptive three-year study (2011-2013) at the Maternity services of the General Reference Hospital of Lubao (Lomami Province, Democratic Republic of Congo). Out of a total of 1158 live babies retained for this study, 378 cases (32.6\%) of birth weight and gestational age abnormalities were noted: $12.7 \%$ of birth and $19.9 \%$ for gestational age anomalies. Premature was much observed $(\mathrm{n}=165$ or $14.2 \%)$ followed by dysmature ( $\mathrm{n}=99$ or $8.6 \%)$, post-term ( $\mathrm{n}=66$ or $5.7 \%)$, and macrosomes $(\mathrm{n}=48$ or $4.1 \%)$. These anomalies had resulted in 122 cases (10.5\%) of early neonatal
\end{abstract}


Copyright $\odot 2017$ by authors and Open Access Library Inc.

This work is licensed under the Creative Commons Attribution International License (CC BY 4.0).

http://creativecommons.org/licenses/by/4.0/

Open Access deaths. Premature and post-mature were significantly more at risk of mortality than dysmature and macrosomes $(\mathrm{p}<0.05)$. These high rates of birth weight and gestational age anomalies and their associated mortalities attest to the need for rapid and concerted control actions. Birth weight and gestational age abnormalities arise as serious health problems to which appropriate responses are required. It would require good follow-up and care for pregnancy and newborn.

\section{Subject Areas}

Nursing, Pediatrics, Public Health

\section{Keywords}

Dysmature, Lubao, Macrosoma, Premature, Post-Term

\section{Introduction}

The World Health Organization (WHO) sets out the groups of neonatal pathologies including neonatal infections, perinatal asphyxia, congenital malformations and birth weight anomalies (Dysmaturity, Macrosomia) and gestational age (Prematurity, Post-maturity) [1]. Anomalies in birth weight and gestational age (ABWGA) are a real public health problem, especially in developing countries where the mortality that accompanies them is high [2]-[9]. In the developing countries, the management of pregnant women and newborns poses even more problems [7] [8] [10] given the limited means and the often inadequate organization of the qualities of care, especially in rural areas [11]. This situation exposes millions of newborns in the world to high morbidity and mortality [1] [7] [11]. South-East Asia and sub-Saharan Africa cumulate neonatal mortality by nearly $60 \%$ of infant mortality and nearly $40 \%$ of infant and child mortality [12]. Anomalies in birth weight and gestational age, with prematurity in the first rank, are recognized as one of the leading causes of newborn deaths in Africa [7] [9] [10] [11]. In Africa, the majority of the population is rural and often less served by health services [7] [9] [12].

In the Democratic Republic of Congo (DRC), there are provinces where there are no gynecologists, obstetricians and pediatricians. These specialists are important elements in the care of pregnant women and children. This is the case of the province of Lomami and the territory of Lubao in particular. This situation exposes certain newborns (NB) whose clinical condition requires the expertise of the specialist (Obstetrician or pediatrician).

In the medical literature, birth weight and gestational age abnormalities are approached in isolation, so the overall weight of these pathologies seems to be ignored in neonatal medicine. This is where we come up with the idea of approaching this study. The objective of this work is to determine the overall frequency and early neonatal mortality of birth and gestational age anomalies in our environment. It will help health decision makers to get an idea about neonatal health in the territory of Lubao (DR. Congo). 


\section{Patients, Materials and Methods}

\subsection{Site of the Study}

This study was carried out at Lubao Generals Reference Hospital (GRH). The Lubao GRH is located in the Lubao City and Territory, Lomami Province, Democratic Republic of Congo (Figure 1).

The territory of Lubao (area 22,480 $\mathrm{Km}^{2}$ and population estimated at 1,580,069 inhabitants) is a deconcentrated administrative entity whose capital, located 200 $\mathrm{km}$ from Kabinda bears the same name. It is subdivided into four administrative areas and three health zones: Bekalebwe (Kamana Health Zone), Tshofa (Tshofa Health Zone), Lubao and Kisengwa (Lubao Health Zone). The population is predominantly of the Songe (or Ba Songye) ethnic group.

The General Reference Hospital of Lubao (GRH) is the only hospital of the Lubao Health Zone which receives all the patients of the sectors of Lubao and Kisengwa. There are three general practitioners physicians and nurses of all levels (A1, A2 and A3). The health center furthest from its areas action is one 178 kilometers (=Kafumbe health center). The maternity ward has a capacity of 20 beds and is a neonatology unit. There are no incubators or temperature incubators for newborns (NB). There are even times when some essential medicines are lacking

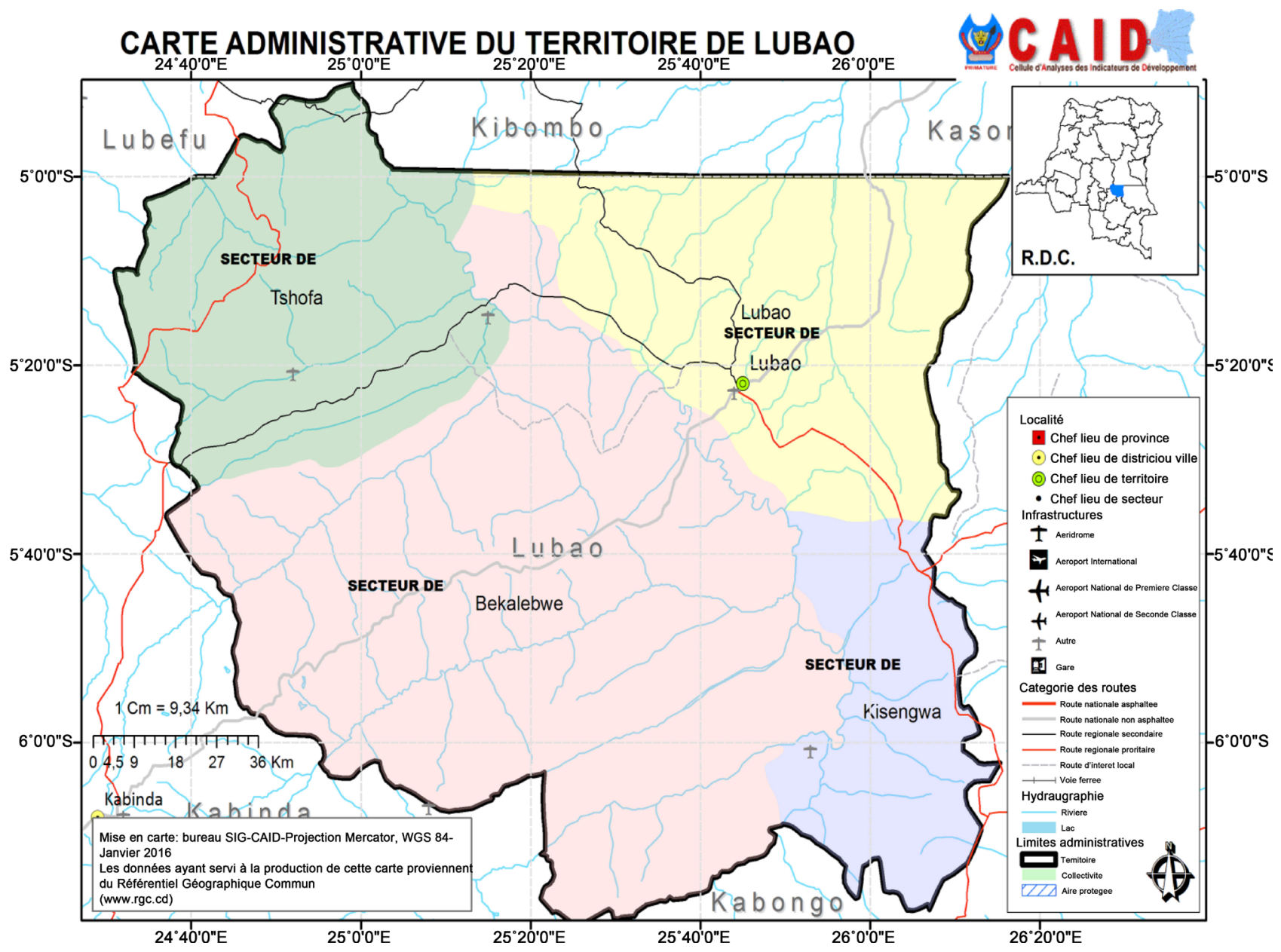

Figure 1. Map of Lubao territory, Lomami Province, DRC. Source: CAID: www.caid.cd. 
and private pharmacies are needed (See

www.caid.cd.index.php/data-by-province-administrative/province-of-lo).

\subsection{Design of the Study}

This was a retrospective and descriptive study carried out from January 2011 to December 2013, there three years. Included in this study was any newborn born from a monofetal pregnancy and whose birth weight anomalies (Macrosomia and Dysmaturity) and gestational age (prematurity and post-maturity) had been met the study parameters. The parameters studied included:

- For the mother: the date of the last menstrual period, the number of prenatal consultations (ANC), parity and age.

- For the newborn: sex, gestational age, birth weight and prognosis in the early neonatal period.

We did not widen the parameters (delivery pathways, delivery patterns, newborn size, maternal history, etc.) to look for under our objective.

To determine gestational age (GA), we referred to the date of the last menstrual period (following the near absence of ultrasound before the twelfth week of amenorrhea and during pregnancy) and the neurological and morphological maturity criteria of the newborn.

To avoid confusion that may arise in particular regarding premature infants (true, macrosomes and hypotrophic), the definitions of ABWGA in this study include:

- Macrosome [13] (fetal macrosomia): NB of birth weight $\geq 4000 \mathrm{~g}$ and $\mathrm{GA} \geq 37$ amenorrhea weeks.

- Premature [3] [7] [10]: NB of which GA $\leq 36$ amenorrhea weeks. In this study, regardless of birth weight, premature new born was included and considered premature.

- Dysmature [11]: NB of birth weight $<2500 \mathrm{~g}$ and $\mathrm{GA} \geq 37$ amenorrhea weeks.

- Post-term [11]: NB whose GA $\geq 42$ amenorrhea weeks.

Out of 1324 births registered in delivery registries and partogrammes at maternity service of the GRH of Lubao, $1158 \mathrm{NB}$ (87.5\%) were selected according to the inclusion criteria. To process the data from this study, the usual calculations including Frequency, Binomial repartition, Means and Chi-squared at significant threshold $\mathrm{p} \leq 0.05$ were used.

\section{Results}

Out of a total of 1158 newborns retained for this study, 378 cases of birth weight (BW) anomalies and gestational age were recorded or 32.6\%. Among the ABWGAs, gestational age abnormalities (GAA) were the most common $(n=231,19.9 \%)$ followed by birth weight anomalies (BWA) $(\mathrm{n}=147,12.7 \%)$ (Figure 2).

The characteristics of the mothers of children with ABWGA revealed that most women were aged 14 to 25 years $(n=197,52.1 \%)$, primiparous $(n=147,38.9 \%)$ and who did not correctly follow prenatal consultations (Table 1 ). The mean age 


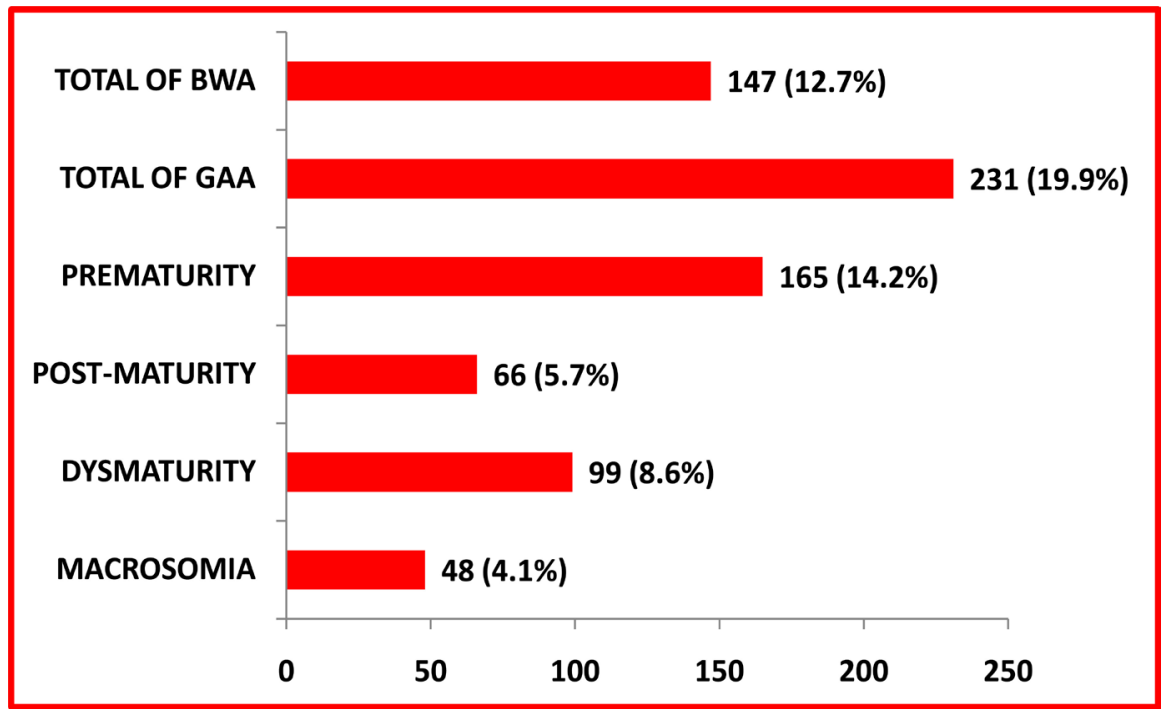

Figure 2. Types of anomalies in birth weight and gestational age among live births $(\mathrm{n}=$ 1158).

Table 1. Characteristics of newborns mothers with anomalies in birth weight and gestational age (Age, Parity and follow-up prenatal consultations).

\begin{tabular}{ccc}
\hline Characteristics & $\mathrm{n}$ & $\%$ \\
\hline Age (years) & 197 & 52,1 \\
{$[14-26[$} & 147 & 38,8 \\
{$[26-38[$} & 34 & 9,0 \\
{$[38-50[$} & & \\
Parity & 147 & 38,9 \\
Primiparous & 73 & 19,3 \\
Pauciparous & 76 & 20,1 \\
Multiparous & 82 & 21,7 \\
Grand multiparous & & \\
Prenatal consultations or visits & 89 & 23,5 \\
No one & 67 & 17,7 \\
1 & 89 & 23,5 \\
2 & 110 & 29,1 \\
3 & 23 & 6,1 \\
$\geq 4$ & & \\
\hline
\end{tabular}

Means age: $27.9 \pm 1.5$ ans (Sd); Extremes: 14 - 48 ans.

was $27.9 \pm 1.5$ years with the extremes of 14 to 48 years. No prenatal visits were followed by 89 women (23.5\%). Only 110 women who had given birth followed three prenatal consultations (29.1\%). Among the abnormalities of birth weight and gestational age, prematurity $(\mathrm{n}=165$ or $14.2 \%)$ was the most encountered followed by dysmaturity ( $\mathrm{n}=99$ or $8.6 \%$ ), post-maturity $(\mathrm{n}=66$ or $5.7 \%)$ and Macrosomia ( $n=48$ or $4.1 \%$ ). The difference observed in the different categories 
of ABWGAs (GAA and BWA) was statistically significant ( $<0.05)$ (Figure 2).

Figure 3 provides information on the sex of newborns. In $52.4 \%$ of cases $(n=$ 198), NB were male whereas girls accounted for $47.6 \%$, or 180 newborns. Compared with sex, macrosomes, post-term and prematurity were predominantly male with 56.2\% $(\mathrm{n}=27), 65.2 \%(\mathrm{n}=43)$ and 50.3\% $(\mathrm{n}=83)$. The difference observed between the male and female sex was statistically significant for the post-term ( $\mathrm{p}$ $<0.05)$.

In this study, early neonatal mortality was $10.5 \%(\mathrm{n}=122)$ among live births $(\mathrm{n}=1158)$. Premature were the most affected, followed by post-mature, dysmature and macrosome, respectively with $6.6(\mathrm{n}=77), 2.3 \%(\mathrm{n}=27)$, and $1.3 \%(\mathrm{n}=15)$ and $0.3 \%(n=3)$ (Figure 4$)$.

GAAs were significantly the leading causes of early neonatal deaths $(\mathrm{p}<0.05)$ (Table 2 and Figure 4). Macrosomes were less concerned than premature infants (6.2\% than $46.5 \%)$. Indeed, the order of early neonatal deaths was as follows: Prematurity $>$ Post-maturity $>$ Dysmaturity $>$ Macrosomia.

\section{Discussion}

The health of the NB remains a major concern of the WHO [1] [12]. Africa is

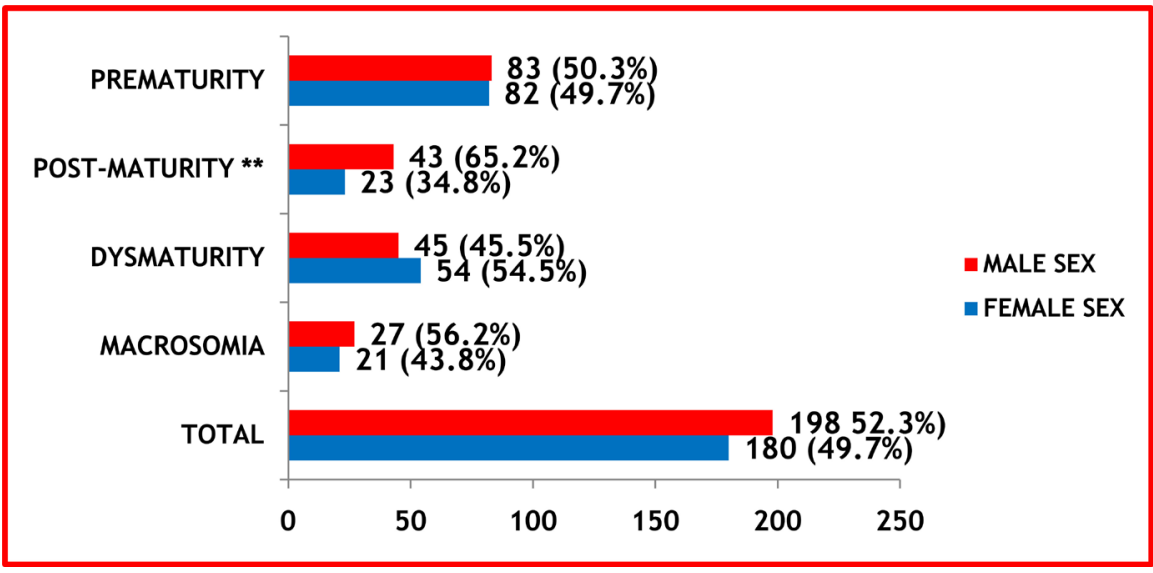

Figure 3. Gender of newborns with anomalies in birth weight and gestational age. ${ }^{*} \mathrm{p}<$ 0.05 .

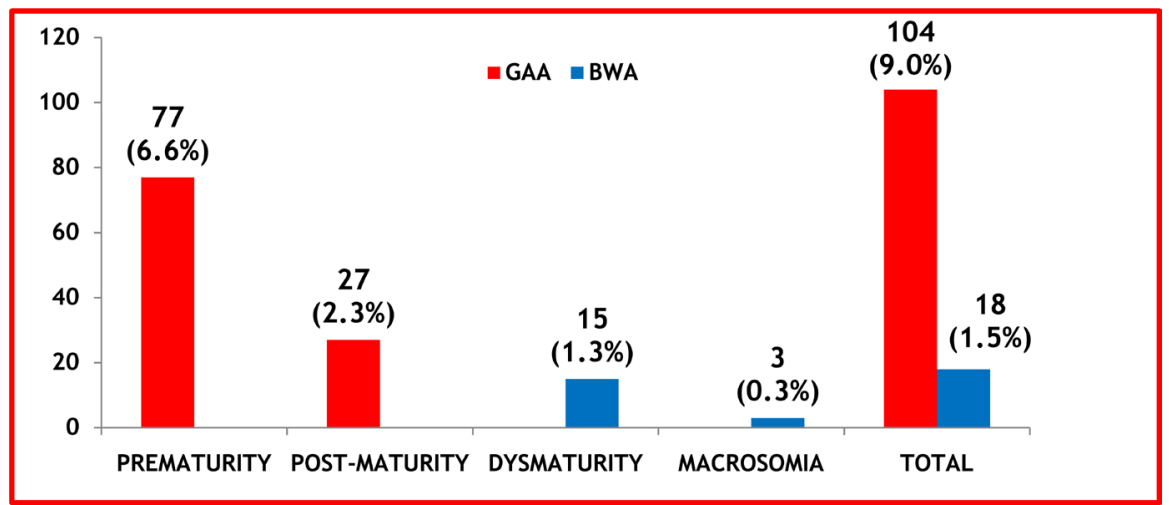

Figure 4. Prognosis of newborns with anomalies in birth weight and gestational age in relation to all births in the early neonatal period $(n=1158)$. 
Table 2. Prognosis of newborns with anomalies in birth weight and gestational age in early neonatal period.

\begin{tabular}{ccccc}
\hline ABWGA & Total n (\%) & As well n (\%) & Deaths n (\%) & P \\
\hline GAA & $231(100)$ & $127(55.0)$ & $104(45.0)$ & \\
PREMATURE & $165(100)$ & $88(53.5)$ & $77(46.5)$ & \\
POST-MATURE & $66(100)$ & $39(59.1)$ & $27(40.9)$ & S $^{*}$ \\
BWA & $147(100)$ & $129(87.8)$ & $18(12.2)$ & \\
DYSMATURE & $99(100)$ & $84(84.8)$ & $15(15.2)$ & \\
MACROSOME & $48(100)$ & $45(93.8)$ & $3(6.2)$ & \\
Total n (\%) & $378(100)$ & $256(67.7)$ & $122(32.3)$ & \\
\hline
\end{tabular}

$\mathrm{S}^{*}$ : The difference between GAA and BWA in death groups is statistically significant.

the continent with high birth and infant mortality rates [10] [12]. We conducted this study in women with a profile of parturients whose average age was $27.9 \pm$ 1.5 years, mostly primiparous (38.9\%) and whose pregnancy monitoring was insufficient. Our objective was to determine the overall frequency of anomalies in birth weight and gestational age in our environment. There was hardly any indepth study of each type of ABWGA. After analyzing the results, BWA (macrosomes and dysmature) and GAA (premature and post-term) constitute a real public health problem in Lubao with $12.7 \%$ and $19.9 \%$ respectively, i.e. an overall frequency of $32.6 \%$. Thus, one in three newborns carries an ABWGA. It would seem that this frequency is higher. This high frequency can be explained mainly by the poor socioeconomic conditions of a large part of the population, inadequate prenatal consultations and the high prevalence of malaria in the region. In our context, some additional factors would be associated but studies would be required. Our work is limited to determining the frequency of ABWGA. Indeed, malaria and poor follow-up of pregnancies have been incriminated in the occurrence of different anomalies of birth weight and gestational age in the world [3] [7] [8] [10] [11]. Male NBs were the most affected (52.4\%) without being statistically significant. In the medical literature consulted in various search engines, no study had approached the ABWGAs as a whole. This situation limits our discussion by the fact that this study seems to be the first.

In comparison with live births, prematurity was the first ABWGA encountered (14.2\%) followed by dysmaturity (8.6\%), post-maturity (5.7\%) and macrosomia (4.1\%). The incidence of prematurity in this series of studies is close to that of certain African authors: Pambou et al. [4] in the Republic of the Congo 16.8\%, Yed et al. [13] in Burkina Faso 15.88\%, Chiesa et al. [14] in Gabon $11.8 \%$ and Balaka et al. [15] in Togo 11.3\%. The results of Tietche et al. [16] 21.5\%, Nagalo [3] 33.6\% and Nyenga [7] 43\% in the DRC were higher than what we met in Lubao. On the other hand, Cissé et al. [5], Kalume et al. [17] and Bernardi [18] had mentioned frequencies lower than our results.

The DRC is among the top 10 countries with the highest prevalence rate of prematurity despite efforts to reduce it [7]. 
Table 3 reports the frequencies of the different birth and gestational age anomalies according to authors and countries.

While published work on infant mortality ( 0 - 5 years) is readily available, this is still not the case for neonatal mortality in sub-Saharan Africa. This situation is certainly due to the failure of vital demographic data and the numerous deliveries and deaths of newborn babies at home [9].

In this study series, the mortality rate of newborns in the early neonatal period following ABWGA was $10.5 \%$, that is to say at least one in ten newborns died after birth. This rate represents $32.3 \%$ of NB with ABWGA. The gestational age abnormalities, already mentioned more frequently, are also significantly the most affected. Neonatal mortality remains a concern for any health program [1] [10] [12] and remains an indicator of the quality of neonatal health [9] [12] [19]. In our context, it is very high and requires exceptional measures from the Ministry of Public Health and its partners. We dare to believe that the lack of necessary resources (obstetrician, neonatologist, incubator, heating table, oxygenotherapy, etc.) for the management of this fragile NB (ABWGA) would be the basis of this great mortality. Early neonatal mortality was $16 \%$ in Ivoire Coast [9] and $27.4 \%$ in Senegal [5]. The overall neonatal mortality (early and late) was $24.15 \%$ in Antananarivo (Madagascar) [19] and 16.7\% in the Bukavu Provincial Hospital (DRC) [12]. No study, apart from this, shows the early neonatal mortality associated with ABWGA.

Among the newborns with ABWGA, prematurity was the first cause of NB deaths with ABWGA (46.5\%) followed by post-term (40.9\%), dysmature (15.2\%)

Table 3. Frequency of ABWGAs in the medical literature.

\begin{tabular}{cccccc}
\hline Authors & Country & Premature & Post-term & Macrosome & Dysmature \\
\hline Our study & DRC & $14.2 \%$ & $5.7 \%$ & $4.1 \%$ & $8.6 \%$ \\
Iloki [20] & Morocco & & & $4.09 \%$ & \\
Laghzaoui [21] & Morocco & & $7.5 \%$ & \\
Dias [22] & Morocco & & & $9 \%$ \\
Djadou [23] & Togo & & & $11 \%$ \\
Ndiaye [11] & Senegal & & & $9.1 \%$ \\
Balaka [15] & Togo & $11.1 \%$ & & & \\
Nagalo [3] & Burkina Faso & $33.6 \%$ & $2.3 \%$ & & \\
Tietche [16] & Cameroon & $33.6 \%$ & & & \\
Kakundji [24] & DRC & & & & \\
Mumba [8] & DRC & & & & \\
Nyenga [7] & DRC & $43 \% * *$ & & \\
Fuchs [25] & France & $6.6 \%$ & & \\
Butali [26] & Nigeria & $16.8 \%$ & & \\
Ezewui [27] & Nigeria & & & & \\
\hline
\end{tabular}

**: Transfered cases from others medical centers represent $67 \%$. 
and macrosome (6.2\%). This same observation was evoked by Ndiaye, Cissé, Nyenga and Mutombo [5] [7] [9] [11]. On the other hand, mortality was very low in the rank of macrosome (Table 2 and Figure 4). The preterm infant is a fragile being exposed to several complications (return to fetal circulation, hypoglycemia, hypothermia, respiratory distress, peri-ventricular leucomalacia, periventricular hemorrhage, hyponatremia, hypocalcemia, infections, etc.) could have a dominant role in the incidence of mortality. Mortality in premature infants (Table 2) is close to Ye et al. [13] in Burkina Faso with $40.4 \%$ but lower than Balaka et al. [15] 30.1\% and Cissé et al. [5] 30.7\%.

Mortality due to dysmaturity among live births in our series remains far lower than that reported by DIAS [22] in Morocco: $1.3 \%$ than 23\% (but for DIAS, it was a question of the early and late mortality of All newborns regardless of ABW$\mathrm{GA})$.

The frequency and early neonatal mortality of APNAG would be underestimated in our series, in case the many home births are included. Nevertheless, these results confirm the high frequency of ABWGA and the arguments that Africa in general and the DRC in particular are the places where the newborns have a higher risk of mortality [5] [7] [9] [10] [12] [19].

The proportion of ABWGAs, especially in rural areas, should be of concern to health decision-makers. Efforts to improve the survival of mothers and newborns should be encouraged. Prospective cohort studies are very necessary to complement the results of this study, particularly with regard to the association factors and fate of these children with birth weight and gestational age abnormalities.

\section{Conclusion}

Anomalies in birth weight and gestational age affect $32.6 \%$ of newborns and stand as serious health problems to which appropriate responses are required. The rate of early neonatal mortality (10.5\%) remains very high. Efforts must be urgently made at all levels in terms of population education, monitoring and management of women from beginning of pregnancy up to the postpartum periods. The conditions for NB care, in particular those with ABWGA with predominance in the first place by prematurity, had to be improved. In waiting for the public authorities to affect the qualified personnel (specialists in neonatology and obstetrics), we advocate, in addition to the equipment to be provided for the care of the $\mathrm{NB}$, the continuing training of the health personnel in the mother's health and the new-born.

\section{Acknowledgements}

We would like to thank the maternity nurses at Lubao Generals Reference Hospital for their good cooperation during the data collection phase: Your bravery to save the lives of mothers and newborns with meager resources is truly a source of inspiration.

Also, the authors would like to thank Jacques NSOMWE ABEDI ${ }^{\dagger}$ and Marie $\mathrm{KISEME}^{\dagger}$ for their help in data collects. 


\section{Conflict of Interest}

The authors do not declare any conflicts of interest in connection with this study.

\section{References}

[1] WHO Newborn: Reducing Mortality [OMS. Nouveau-né: Réduire la mortalité] (2016) Aide-Mémoire No. 333.

[2] Ancel, P.-Y. (2012) An Increasing Frequency: Epidemiology of Prematurity [Une fréquence en augmentation: Epidémiologie de la prématurité]. Revue du Praticien, 62, 362-365.

[3] Nagalo, K., Dao, F., Badiel, R., Sawadogo, O., Housseini Tall, F.H. and Ye, D. (2015) Epidemiological, Clinical and Prognostic Aspects of Preterm Birth over 10 Years in Ouagadougou (Burkina Faso). Journal of Pediatric Sciences, 7, e231. https://doi.org/10.17334/jps.69907

[4] Pambou, O., Nisika-Kaya, P., Ekoundzola, J.R. and Mayanda, F. (2006) Live PreTerm Birth in Brazzaville UTH [Naissance vivantes avant-terme au CHU de Brazzaville]. Cahiers Santé, 16, 185-189.

[5] Cissé, C.T., Martin, S.L., Ngoma, S.J., Mendes, V. and Diadhiou, F. (1996) Early Neonatal Mortality at Dakar CHU Maternity: Current Situation and Evolutionary Trends between 1987 and 1994 [Mortalité néonatale précoce a la maternité du CHU de Dakar: Situation actuelle et tendances évolutives entre 1987 et 1994]. Médecine d Afrique Noire, 43, 155-158.

[6] Lejeune, C. (2008) Precarious and Premature [Précarité et prématuré]. Journal de Pédiatrie et de Puériculture, 21, 344-348. https://doi.org/10.1016/j.jpp.2008.09.008

[7] Nyenga, M.A., Mwananteba, A., Kanteng, A.W., Lubala, K.T. and Yaba, A. (2013) Profile and Mortality Risk in Preterm Infants at Sendwe/Lubumbashi Hospital, DR Congo [Profil et risque de mortalité chez les prématurés à l'hôpital Sendwe/Lubumbashi, RD Congo]. Revue de Pédiatrie du fleuve Congo, 1, 29-37.

[8] Mumba Mukandila, A., Balayi Miteo, A., Kadima Mutombo, C. and Biayi Mikenji, J. (2016) Fetal Macrosomia in Urban Areas: Prevalence, Determinants and Outcome of Childbirth (about 154 Cases in Mbuji-Mayi) [La macrosomie foetale en milieu urbain: Prévalence, facteurs déterminants et issue de l'accouchement (à propos de 154 cas à Mbuji-Mayi)]. Revue Medicale des grands Lacs, 7, 25-29.

[9] Mutombo, T. (1993) Neonatal Mortality in a Rural Hospital: Case of the Protestant Hospital in Dabou (Côte d'Ivoire) [Mortalité néonatale dans un hôpital rural: Cas de l'hôpital protestant de Dabou (côte d'Ivoire)]. Medecine dAfrique Noire, 40, 471-479.

[10] Balegamire Safari, J., Bisimwa Nkemba, A., Namegabe Bahizire, E., Bisimwa Balaluka, G., Bahwere, P., Donnen, P., et al. (2015) A Comparative Study of the Mortality and Pathologies Responsible for Mortality in South Kivu in the Democratic Republic of Congo before and after the Period of Chronic Security Instability [Etude comparative de la mortalité et des pathologies responsables de la mortalité au Sud-Kivu en République Démocratique du Congo avant et après la période d'instabilité sécuritaire chronique]. Medecine d Afrique Noire, 62, 581-597.

[11] Ndiaye, O., Fall, A.L., Grame, A., Sylla, A., Gueye, M., Cissé, T., et al. (2006) Etiological Factors of Prematurity in the Zinguinchor Regional Hospital Center (Senegal) [Facteurs étiologiques de la prématurité au centre hospitalier régional de Zinguinchor (Sénégal)]. Bulletin de la Société de Pathologie Exotique, 99, 113-114.

[12] Kambale, R., Maseka, A., Bwija, J., Bapolisi, W., Bashi, J., Masumbuko, B., et al. (2016) Risk Factors Associated with Neonatal Mortality in a Tertiary-Level Hospital 
in the Democratic Republic of Congo [Facteurs de risque associés à la mortalité néonatale dans un hôpital de niveau tertiaire en République Démocratique du Congo]. Medecine d Afrique Noire, 63, 401-408.

[13] Ye, D., Kam, K.L., Sanou, I., Traore, A., Dao, L., Koueta, F., et al. (1999) Epidemiological and Evolutionary Study of Prematurity in the Neonatology Unit of the CHU-Yo of Ouagadougou (Burkina Faso) [Etude épidémiologique et évolutive de la prématurité dans l'unité de néonatologie du CHU-Yo de Ouagadougou (Burkina Faso)]. Annales de Pediatrie, 46, 643-648.

[14] Chiesa Moutandou-Mboumba, S. and Mounanga, M. (1999) Preterm in Gabon: A Medical and/or Social Problem? [La prématuré au Gabon: Problème médical et/ou de société ?]. Medecine d'Afrique Noire, 46, 435-441.

[15] Balaka, B., Baeta, S., Agbèrè, A.D., Boko, K., Kessie, K. and Assimadi, K. (2002) Risk Factors Associated with Prematurity at the Lomé University Hospital, Togo [Facteurs de risque associés à la prématurité au CHU de Lomé, Togo]. Bulletin de la Société de Pathologie Exotique, 95, 280-283.

[16] Tietche, F., Ngoufack, G., Kago, I., Mbonda, E., Koki Ndombo, P.O. and Leke, R.I. (1998) Etiological Factors Associated with Intra-Uterine Growth Retardation in Yaoundé (Cameroon): Preliminary Study [Facteurs étiologiques associes au retard de croissance intra-utérine à Yaoundé (Cameroun): Etude préliminaire]. Medecine $d$ Afrique Noire, 45, 377-380.

[17] Kalume, M. and Kizonde, K. (2006) Early Neonatal Mortality of Preterm Infants in Lubumbashi: Risk Factors [Mortalité néonatale précoce du prématuré à Lubumbashi: Facteurs de risque]. Medecine d Afrique Noire, 53, 343-348.

[18] Berardi, J.C. (1992) The Premature Medical Decision: Analysis of a Retrospective Study on 18 Maternities of the Parisian Periphery [Le prématuré de décision médicale: Analyse d'une étude rétrospective portant sur 18 maternités de la Périphérie parisienne]. Journal de Gynécologie Obstétrique et Biologie de la Reproduction, 21, 943-946.

[19] Ranaivoarisoa, R., Rakotoarisoa, H., Raobijaona, H., Rakotomahefa, M. and Rabeatoandro, S. (2011) Morbidity and Mortality of Children in Pediatric Wards in Antananarivo [Morbidité et mortalité des enfants au service de pédiatrie à Antananarivo]. Medecine d Afrique Noire, 58, 5-8.

[20] Iloki, L.H., Itoua, C., Mbemba Moutounou, G.M., Massouama, R. and Koko, P.S. (2014) Fetal Macrosomia: Risk Factors and Materno-Fetal Complications in Brazzaville (Republic of Congo) [Macrosomie fotale: Facteurs de risque et complications materno-foetale à Brazzaville (République du Congo)]. Medecine $d$ Afrique Noire, 61, 479-486.

[21] Laghzaoui Boukaidi, M., Bouhya, S., Hermas, S., Bennani, O. and Aderdour, M. (2004) Epidemiology of Macrosomia [Epidémiologie de la macrosomie]. Maroc Médical, 26, 99-102.

[22] Dias, C. and Aboussad, A. (2013) Epidemiological, Clinical, Etiological Profiles and Short-Term Evaluation of RCIU Hospitalized in the Neonatal and Neonatal Resuscitation Department of CHU Mohammed VI during the Year 2010. Faculty of Medicine and Pharmacy-Marrakech [Profils épidémiologique, clinique, étiologiques, et évaluation à court terme des RCIU hospitalisés au service de Néonatalogie et de Réanimation Néonatale du CHU Mohammed VI durant l'année 2010. Faculté de Médecine et de Pharmacie-Marrakech]. Maroc.

[23] Djadou, K., Sadzou-Hetsu, K., Tatagan-Agbi, K., Assimadi, K. and Lapillome, A. (2005) Anthropometric Parameters, Frequency and Risk Factors of Intrauterine Growth Retardation in Term Neonates in North Togo [Paramètres anthro- 
pométriques, fréquence et facteurs de risque du retard de croissance intra-utérin chez les nouveau-nés à terme dans la région du Nord-Togo]. Archives de Pédiatrie, 12, 1320-1326. https://doi.org/10.1016/j.arcped.2005.03.051

[24] Kakudji Luhete, P., Mukuku, O., Mubinda Kiopin, P., Mwembo Tambwe, A. and Kalenga Muenze Kayamba, P. (2016) Fetal Macrosomia in Lubumbashi: Risk Factors and Maternal and Perinatal Prognosis [Macrosomie fotale à Lubumbashi: Facteurs de risque et pronostic maternel et périnatal]. Pan African Medical Journal, 23, 166. https://doi.org/10.11604/pamj.2016.23.166.7362

[25] Fuchs, F., Bouyer, J., Rozenberg, P. and Senat, M.V. (2013) Adverse Maternal Outcomes Associated with Fetal Macrosomia: What Are the Risk factors beyond Birthweight? BMC Pregnancy and Childbirth, 8, 90.

https://doi.org/10.1186/1471-2393-13-90

[26] Butali, A., Ezeaka, C., Ekhaguere, O., Weathers, N., Ladd, J., Fajolu, I., et al. (2016) Characteristics and Risk Factors of Preterm Births in a Tertiary Center in Lagos, Nigeria. Pan African Medical Journal, 24, 1-7.

https://doi.org/10.11604/pamj.2016.24.1.8382

[27] Ezegwui, H.U., Ikeako, L.C. and Egbuji, C. (2011) Fetal Macrosomia: Obstetric Outcome of 311 Cases in UNTH, Enugu, Nigeria. Nigerian Journal of Clinical Practice, 14, 322-326. https://doi.org/10.4103/1119-3077.86777

Submit or recommend next manuscript to OALib Journal and we will provide best service for you:

- Publication frequency: Monthly

- 9 subject areas of science, technology and medicine

- Fair and rigorous peer-review system

- Fast publication process

- Article promotion in various social networking sites (LinkedIn, Facebook, Twitter, etc.)

- Maximum dissemination of your research work

Submit Your Paper Online: Click Here to Submit

Or Contact service@oalib.com 